\title{
IMPLEMENTATION OF ANALYTIC HIERARCHY PROCESS (AHP) AS A DECISION SUPPORT TOOL FOR SELECTION OF ROBOT FOR SPOT WELDING OPERATION
}

\author{
Rajani $\mathbf{P}^{1}$, JawaharBabu $\mathbf{A}^{2}$ \\ ${ }^{1}$ Department of Basic Science and Humanities, Gudlavalleru Engineering College, Gudlavalleru \\ ${ }^{2}$ Department of Mechanical Engineering, Gudlavalleru Engineering College, Gudlavalleru
}

\begin{abstract}
Flexible production lines are most essential for any lean manufacturing system for cost effectiveness. Automobile industry is extensively making use of lean manufacturing philosophy where reduction of waste is paramount importance without sacrificing the quality. Production of an automobile consists of number of phases in which fabrication of body by portable spot welding guns using robots is a significant stage. Robotic Spot welding operation is accomplished to manufacture the body of the automobile, because of its inherent accuracy and repeatability. Robot is a programmable machine which offers flexibility to switch over from one type of model of automobile to another type of model swiftly. But selection of an appropriate robot for the desired task to be accomplished is a crucial decision to be taken. Many factors are to be considered before arriving at an apt decision. Thescenario of this sort may be considered as multi-criteria decisionmaking (MCDM) problem. Though many techniques are available to solve problems of this type, Analytic Hierarchy Process (AHP) has been selected, because of its strong mathematical basis. In the present paper AHP is implemented to address this MCDM problem which acts as a decision support tool to select an appropriate robot for spot welding operation.
\end{abstract}

Six criteria and eighteen sub-criteria have been considered to rank the robots. Attributes of three alternatives have been compared against criteria and sub-criteria chosen to evaluate the candidate robot

Keywords: Lean manufacturing, robotic spot welding, multi-criteria decision making, analytic hierarchy process $(A H P)$.

\section{INTRODUCTION}

Lean manufacturing aims to produce a product as desired by the customer at the right time by minimizing all non-value added activities in production (James Womack 2007). In the literature, value is simply defined as what the customer is willing to pay for. Non-value added activities are generally understood to be either waste, or incidental activities that are necessary but add no value to the product. The best example of a non-value added activity is quality assurance. Quality inspections do not add value to a product. They simply identify defects before they reach the consumer. Inherent motive of lean manufacturing is first time perfect quality (MP Groover 2001). But product quality is a function of number of parameters. They are equipment, raw material, process parameters, and methods to follow [3]. Other things remain same the equipment that is being used plays a vital role in maintaining the desired quality of the product. The equipment or machines used in lean manufacturing must be appropriate to suitthe requirements and also flexible. In the manufacture of automobile bodies spot welding operation is used to join number of sheet metal shapes that are processed in different presses. Spot welding is a process in which two sheet metal parts are fused together at localised points by passing large electric current through the parts where weld is to be made (MP Groover 2012). For car bodies stationary spot welding machine cannot be employed. Obvious choice is use of a portable spot welding gun. The welding gun consists of pair of electrodes and a frame to open and close the electrodes. The welding gun with cables attached is quite heavy and can easily exceed $100 \mathrm{lb}$ in weight. Even with the assistance of overhead hoist system the spot welding gun represents a heavy mass and is difficult to manipulate by a human worker at the high rates of production desired on a car body assembly line. Number of drawbacks was observed with manual spot welding operation (MP Groover 2012). Some of them are poor location of spots, poor quality of the weld, operator fatigue. To overcome these drawbacks human operators are replaced by robots. But there are certain challenges with robotic spot welding. Robot which has to accomplish the spot welding operation should possess sufficient load carrying capacity, accuracy and repeatability, less mass moment of inertia, adequate moments at the wrist joints and multiple degrees of freedom to have access to desired locations on the body of automobile.

\section{LITERATURE REVIEW}

Many attempts have been made in the literature to select a robot for the given application. Fuzzy set theory and hierarchical structural analysis have been used to assess decision make's fuzzy assessment and suitability ratings of 
robot for the chosen criteria (Gin-Shuh Liang and wang M.J 1993). Aperformance measurement tool called operational competitiveness rating (OCRA) and a multi attribute decision making (MADM) tool called technique for order preference by similarity to ideal solution (TOPSIS) have been used for selection of a robot among several alternatives (CelikParkon and Ming Lu Wu 1999). A deterministic quantitative method based on distance based approach (DBA) has been used for evaluation, selection and ranking of robots for the given application (Rishi Kumar and Garg 2010).Analytic hierarchy process (AHP) and TOPSIS methods have been used to select a robot for material handling application (ŞenimÖzgürler and others 2011). While implementing AHP they have considered three criteria and eight sub-criteria for three alternatives.A Decision Support system based on axiomatic principles has been developed for selection of a robot (Mehmet CagatayBahadir and SuleItirSatoglu 2012). In the present work analytic hierarchy process (AHP) has been implemented to select a robot for spot welding operation among three alternatives by considering six criteria and eighteen sub-criteria which are technical in nature.

\section{ANALYTIC HIERARCHY PROCESS (AHP)}

The Analytical Hierarchy Process is a multi-criteria decision making (MCDM) method that helps the decision maker facing a complex problem with multiple, complex and subjective criteria (FarzadTahriri 2008). AHP has been used in many applications in public and private sectors. Some of the applications include manufacturing, logistics, environment, marketing, higher education, business (William Ho 2008; OmkarprasadS.Vaidya 2006).In AHP,the chosen problem must be decomposed into multi-level hierarchical structure, which consists of goal, criteria, subcriteria and alternatives (Sharma M J 2008). At the top level is the goal to be attained. Intermediate levels consist of factors to be considered for evaluation of alternatives. And the bottom level contains alternatives to achieve the goal. Then the expert has to form pair wise comparison matrices, by comparing two criteria at a time based on Saaty's nine point scale (Thomas L Saaty 1990). If the problem involves sub-criteria, pair wise comparison matrices must be formed, by comparing two sub-criteria at a time with respect to the main criterion. Similar pair wise comparison matrices must be formed for alternatives under consideration with respect to each criterion.After a comparison matrix, A has been formed, the priority of the element can be compared by the computation of eigenvalues and eigenvectors with the following formula, where $\mathrm{w}$ is the eigenvector, the weight vector of $\mathrm{A}$, and $\lambda_{\max }$ is the largest eigenvalue of $\mathrm{A}$ : $\mathrm{Aw}=$ $\lambda_{\max } \mathrm{W}$. Next consistency property of the matrix must be checked, by obtaining consistency ratio (CR) which is defined as the ratio of consistency index (CI) and random index $(\mathrm{RI})$. And $\mathrm{CI}$ is obtained by following formula: $\mathrm{CI}=$ $\left.\left(\lambda_{\max }-n\right) / n-1\right)$. Size of the pair wise comparison matrix is $n$. RI depends on the size of the matrix and it is the average CI value of randomly generated comparison matrices for the number of items being considered. By aggregating the relative priorities of the decision elements, overall priority of the decision alternatives can be obtained.

\section{SELECTION OF A ROBOT FOR SPOT WELDING OPERATION}

Quality of the spot welding operation depends on number of parameters [15]. The robot which has to accomplish spot welding operation should have enough load carrying capacity to handle heavy weighing spot welding gun and capacity to move swiftly from one location to another location. Following criteria have been considered for selection of robot. Wrist reach: it is concerned with extension or retraction (in or out movement) of the arm from the vertical centre of the robot. More the wrist reach, farther points of the car body can be reached. Repeatability: It is concerned with the robot's ability to position its wrist or an end effecter attached to its wrist at a point in space that had previously been taught to the robot. In three dimensional spaces, the repeatability errors will surround the programmed point, forming a distribution whose outer boundary can be conceptualized as a sphere. A robot manufacturer typically quotes the repeatability of its manipulator as the radius of idealized sphere, usually expressing the specification as plus or minus a particular value. For a spot welding operation repeatability is very much required for consistent creation of nuggets over the body of the car.Motion range: It is the variation between the movements of individual joints from clockwise direction to anticlockwise direction. It is directly concerned with work volume. Larger the motion range, higher would be the work volume and it can cover more spots on the car body.Maximum speed: It is the pace at which individual joints will rotate in both directions. It decides the production rate.Moment: it is the force multiplied by distance from the point of application of force to pivotal axis. As the spot welding gun weighs around $30 \mathrm{~kg}$ to $40 \mathrm{~kg}$, robot has to effortlessly manoeuvre it at the specified region of the car body.Mass Moment of Inertia: It is the resistance offered by the body for rotation. The robot under consideration is a six jointed articulated robot having three degrees of freedom for the body and arm assembly and three degrees of freedom for wrist assembly with a payload capacity of $100 \mathrm{~kg}$. Handling a portable spot welding gun naturally demands less mass moment of inertia for swift movements over the car body.Hierarchical structure for the present problem is shown in the figure-1. Criteria, sub-criteria and attributes of the three robots under consideration are presented in table-1. 


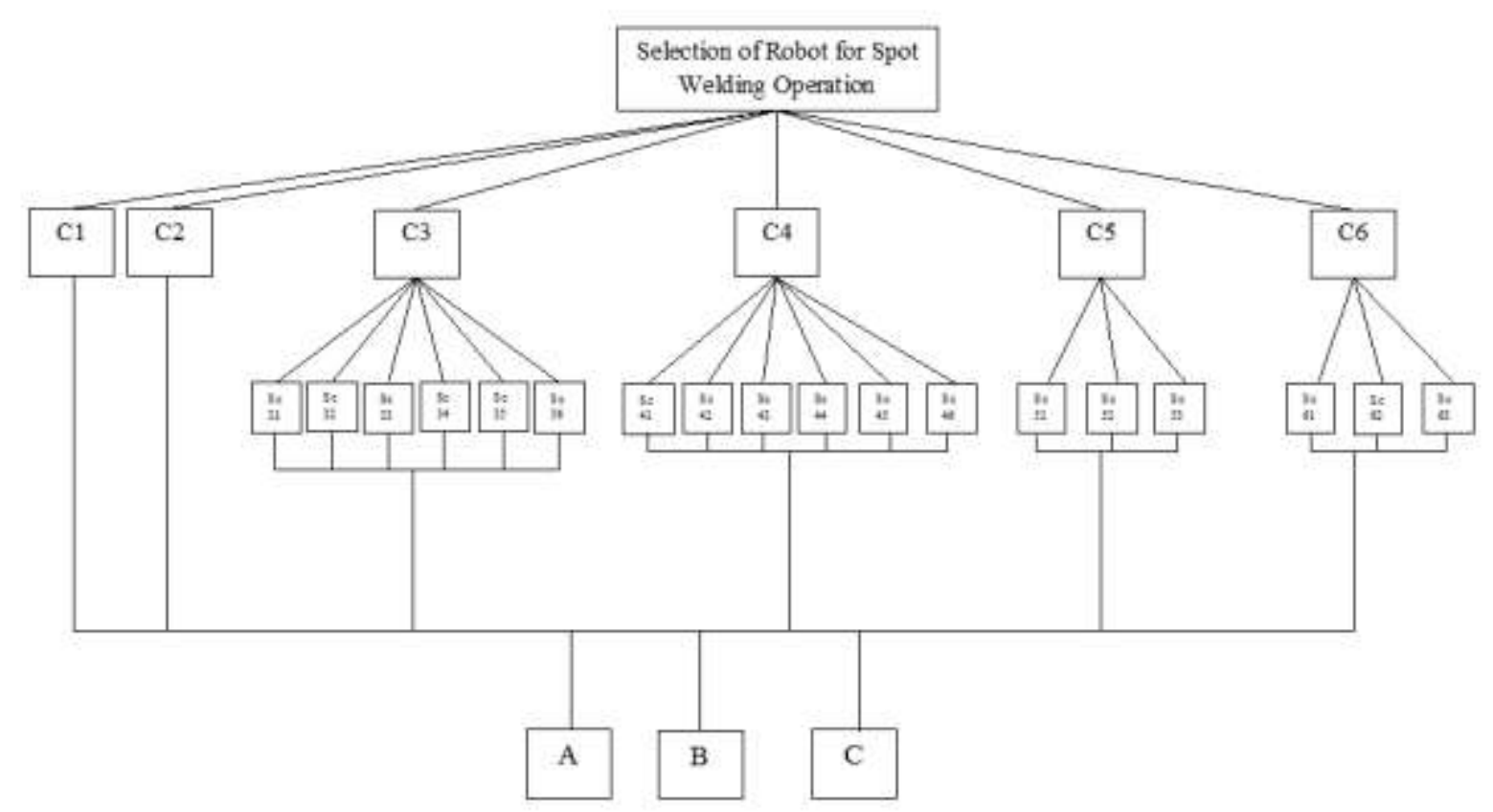

Hierarchy Tree for selection of a Robot for Spot welding operation

Fig-1

Table-1: Criteria, Sub-criteria and attributes of alternatives under consideration $(16,17,18)$

\begin{tabular}{|c|c|c|c|c|c|c|}
\hline SNo & Criteria & & & $\begin{array}{l}\text { Model } \\
\text { A(Kawasaki) }\end{array}$ & Model B(Fanuc) & $\begin{array}{l}\text { Model } \\
\text { C(Motoman) }\end{array}$ \\
\hline $\mathrm{C} 1$ & Wrist reach & & & $1634 \mathrm{~mm}$ & $2230 \mathrm{~mm}$ & $3010 \mathrm{~mm}$ \\
\hline $\mathrm{C} 2$ & Repeatabiity & & & \pm 0.2 & \pm 0.2 & \pm-0.3 \\
\hline \multirow{6}{*}{$\mathrm{C} 3$} & \multirow[b]{6}{*}{ Motion Range } & $\mathrm{SC}_{3,1}$ & $\mathrm{~J} 1$ & +160 & $360($ total $)$ & \pm 180 \\
\hline & & $\mathrm{SC}_{3,2}$ & $\mathrm{~J} 2$ & $+120 /-65$ & 245(total) & $+76 /-60$ \\
\hline & & $\mathrm{SC}_{3,3}$ & $\mathrm{~J} 3$ & $+90 /-80$ & 360 (total) & $+230 /-137.5$ \\
\hline & & $\mathrm{SC}_{3,4}$ & $\mathrm{~J} 4$ & \pm 210 & 720 (total) & $\pm 360^{\circ}$ \\
\hline & & $\mathrm{SC}_{3,5}$ & J5 & \pm 125 & 250 (total) & \pm 130 \\
\hline & & $\mathrm{SC}_{36}$ & J6 & \pm 210 & 720 (total) & $\pm 360^{\circ}$ \\
\hline \multirow{6}{*}{$\mathrm{C} 4$} & \multirow{6}{*}{ Maximum Speed(deg/s) } & $\mathrm{SC}_{4,1}$ & J1 & 135 & 170 & 110 \\
\hline & & $\mathrm{SC}_{4,2}$ & $\mathrm{~J} 2$ & 125 & 140 & 110 \\
\hline & & $\mathrm{SC}_{4,3}$ & $\mathrm{~J} 3$ & 155 & 160 & 110 \\
\hline & & $\mathrm{SC}_{4,4}$ & $\mathrm{~J} 4$ & 200 & 230 & 175 \\
\hline & & $\mathrm{SC}_{4,5}$ & $\mathrm{~J} 5$ & 160 & 230 & 145 \\
\hline & & $\mathrm{SC}_{4,6}$ & J6 & 300 & 350 & 240 \\
\hline \multirow[t]{3}{*}{$\mathrm{C} 5$} & \multirow[t]{3}{*}{ Allowable Moment } & $\mathrm{SC}_{5,1}$ & $\mathrm{~J} 4$ & $830 \mathrm{~N}-\mathrm{m}$ & $690 \mathrm{~N}-\mathrm{m}$ & $833 \mathrm{~N}-\mathrm{m}$ \\
\hline & & $\mathrm{SC}_{5,2}$ & $\mathrm{~J} 5$ & $830 \mathrm{~N}-\mathrm{m}$ & $690 \mathrm{~N}-\mathrm{m}$ & $833 \mathrm{~N}-\mathrm{m}$ \\
\hline & & $\mathrm{SC}_{5,3}$ & J6 & $441 \mathrm{~N}-\mathrm{m}$ & $260 \mathrm{~N}-\mathrm{m}$ & $490 \mathrm{~N}-\mathrm{m}$ \\
\hline \multirow{3}{*}{ C6 } & \multirow{3}{*}{$\begin{array}{l}\text { Allowable Mass Moment of } \\
\text { Inertia }\end{array}$} & $\mathrm{SC}_{6,1}$ & $\mathrm{~J} 4$ & $85 \mathrm{~kg}-\mathrm{m}^{2}$ & $57 \mathrm{~kg}-\mathrm{m}^{2}$ & $75 \mathrm{~kg}-\mathrm{m}^{2}$ \\
\hline & & $\mathrm{SC}_{6,2}$ & J5 & $85 \mathrm{~kg}-\mathrm{m}^{2}$ & $57 \mathrm{~kg}-\mathrm{m}^{2}$ & $75 \mathrm{~kg}-\mathrm{m}^{2}$ \\
\hline & & $\mathrm{SC}_{6,3}$ & J6 & $45 \mathrm{~kg}-\mathrm{m}^{2}$ & $32 \mathrm{~kg}-\mathrm{m}^{2}$ & $25 \mathrm{~kg}-\mathrm{m}^{2}$ \\
\hline
\end{tabular}

Table-2: Pair wise comparison matrix for Criteria vs Criteria

\begin{tabular}{|l|l|l|l|l|l|l|l|}
\hline & C1 & C2 & C3 & C4 & C5 & C6 & $\begin{array}{l}\text { Priority } \\
\text { vector }\end{array}$ \\
\hline C1 & 1 & $1 / 2$ & $1 / 3$ & $1 / 3$ & $1 / 8$ & $1 / 4$ & 0.0415 \\
\hline C2 & 2 & 1 & $1 / 3$ & $1 / 2$ & $1 / 8$ & $1 / 4$ & 0.0569 \\
\hline
\end{tabular}




\begin{tabular}{|l|l|l|l|l|l|l|l|}
\hline C3 & 3 & 3 & 1 & $1 / 2$ & $1 / 5$ & $1 / 3$ & 0.1012 \\
\hline C4 & 3 & 2 & 2 & 1 & $1 / 4$ & $1 / 3$ & 0.1145 \\
\hline C5 & 8 & 8 & 5 & 4 & 1 & 3 & 0.4572 \\
\hline C6 & 4 & 4 & 3 & 3 & $1 / 3$ & 1 & 0.2238 \\
\hline
\end{tabular}

Table-3: Pair wise comparison matrix for sub-criteria vs sub criteria w.r.t $\mathrm{C} 3$

\begin{tabular}{|l|l|l|l|l|l|l|l|}
\hline & $\mathrm{SC}_{3,1}$ & $\mathrm{SC}_{3,2}$ & $\mathrm{SC}_{3,3}$ & $\mathrm{SC}_{3,4}$ & $\mathrm{SC}_{3,5}$ & $\mathrm{SC}_{3,6}$ & $\begin{array}{l}\text { Priority } \\
\text { vector }\end{array}$ \\
\hline $\mathrm{SC}_{3,1}$ & 1 & 3 & 3 & $1 / 4$ & $1 / 5$ & $1 / 5$ & 0.0943 \\
\hline $\mathrm{SC}_{3,2}$ & $1 / 3$ & 1 & $1 / 3$ & $1 / 5$ & $1 / 2$ & $1 / 7$ & 0.0465 \\
\hline $\mathrm{SC}_{3,3}$ & $1 / 3$ & 3 & 1 & $1 / 3$ & $1 / 2$ & $1 / 7$ & 0.0759 \\
\hline $\mathrm{SC}_{3,4}$ & 4 & 5 & 3 & 1 & 2 & 1 & 0.2732 \\
\hline $\mathrm{SC}_{3,5}$ & 5 & 2 & 2 & $1 / 2$ & 1 & $1 / 2$ & 0.1696 \\
\hline $\mathrm{SC}_{3,6}$ & 5 & 7 & 7 & 1 & 2 & 1 & 0.3405 \\
\hline
\end{tabular}

Table-4: Pair wise comparison matrix of sub-criteria vs sub criteria w.r.t $\mathrm{C} 4$

\begin{tabular}{|l|l|l|l|l|l|l|l|}
\hline & $\mathrm{SC}_{4,1}$ & $\mathrm{SC}_{4,2}$ & $\mathrm{SC}_{4,3}$ & $\mathrm{SC}_{4,4}$ & $\mathrm{SC}_{4,5}$ & $\mathrm{SC}_{4,6}$ & $\begin{array}{l}\text { Priority } \\
\text { vector }\end{array}$ \\
\hline $\mathrm{SC}_{4,1}$ & 1 & 2 & $1 / 2$ & $1 / 3$ & $1 / 2$ & $1 / 4$ & 0.0899 \\
\hline $\mathrm{SC}_{4,2}$ & $1 / 2$ & 1 & $1 / 2$ & $1 / 2$ & $1 / 2$ & $1 / 3$ & 0.0806 \\
\hline $\mathrm{SC}_{4,3}$ & 2 & 2 & 1 & $1 / 2$ & 1 & $1 / 2$ & 0.1433 \\
\hline $\mathrm{SC}_{4,4}$ & 3 & 2 & 2 & 1 & 2 & 3 & 0.3052 \\
\hline $\mathrm{SC}_{4,5}$ & 2 & 2 & 1 & $1 / 2$ & 1 & $1 / 2$ & 0.1433 \\
\hline $\mathrm{SC}_{4,6}$ & 4 & 3 & 2 & $1 / 3$ & 2 & 1 & 0.2376 \\
\hline
\end{tabular}

Table-5: Pair wise comparison matrix of sub-criteria vs sub criteria w.r.t C5

\begin{tabular}{|l|l|l|l|l|}
\hline & $\mathrm{SC}_{5,1}$ & $\mathrm{SC}_{5,2}$ & $\mathrm{SC}_{5,3}$ & $\begin{array}{l}\text { Priority } \\
\text { vector }\end{array}$ \\
\hline $\mathrm{SC}_{5,1}$ & 1 & 5 & 7 & 0.7235 \\
\hline $\mathrm{SC}_{5,2}$ & $1 / 5$ & 1 & 3 & 0.1932 \\
\hline $\mathrm{SC}_{5,3}$ & $1 / 7$ & $1 / 3$ & 1 & 0.0833 \\
\hline
\end{tabular}

Table-6: Pair wise comparison matrix of sub-criteria vs sub criteria w.r.t C6

\begin{tabular}{|l|l|l|l|l|}
\hline & $\mathrm{SC}_{6,1}$ & $\mathrm{SC}_{6,2}$ & $\mathrm{SC}_{6,3}$ & $\begin{array}{l}\text { Priority } \\
\text { vector }\end{array}$ \\
\hline $\mathrm{SC}_{6,1}$ & 1 & $1 / 3$ & $1 / 5$ & 0.1038 \\
\hline $\mathrm{SC}_{6,2}$ & 3 & 1 & $1 / 4$ & 0.2311 \\
\hline $\mathrm{SC}_{6,3}$ & 5 & 4 & 1 & 0.6611 \\
\hline
\end{tabular}
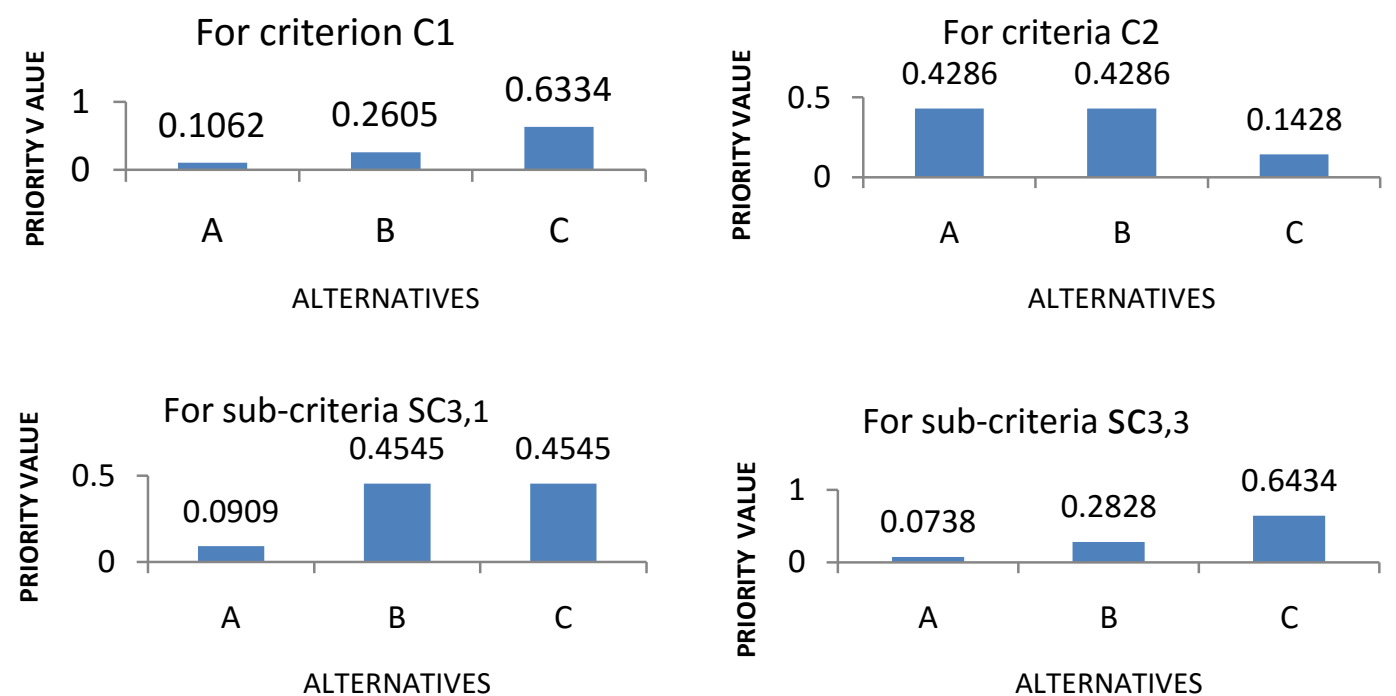


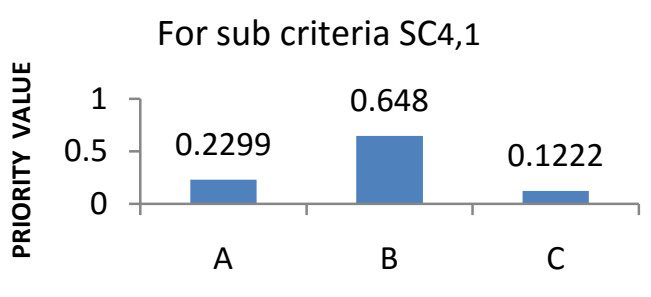

ALTERNATIVES

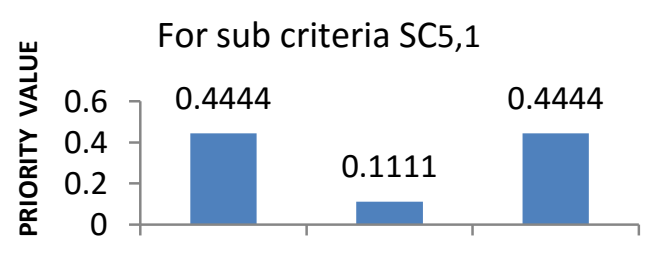

A $\quad$ B $\quad$ C

ALTERNATIVES

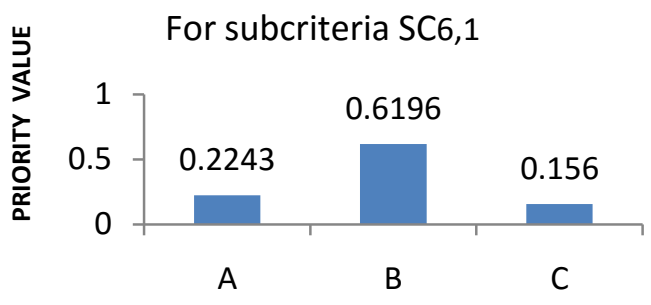

ALTERNATIVES

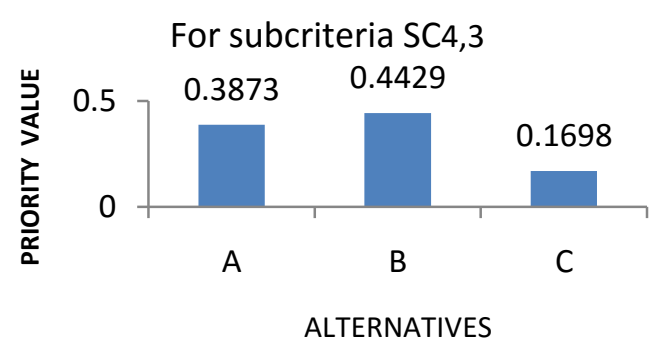

For subcriteria SC5,3

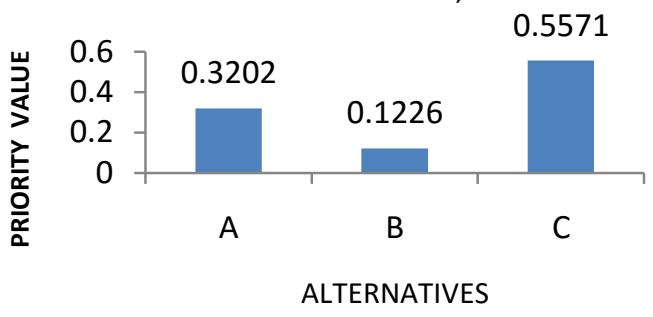

For subcriteria SC6,3

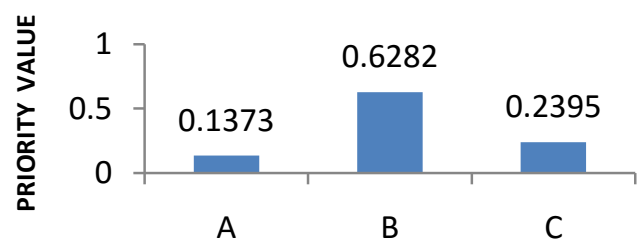

ALTERNATIVES

Fig-2: Priorities of the Alternatives with respect to some of the criteria and sub-criteria

Table-7: Synthesis of priorities of alternatives

\begin{tabular}{|l|l|l|l|}
\hline Criteria & $\mathrm{A}$ & $\mathrm{B}$ & $\mathrm{C}$ \\
\hline $\mathrm{C} 1$ & 0.0044 & 0.0108 & 0.0263 \\
\hline $\mathrm{C} 2$ & 0.0244 & 0.0244 & 0.0081 \\
\hline $\mathrm{SC}_{3,1}$ & 0.0009 & 0.0043 & 0.0043 \\
\hline $\mathrm{SC}_{3,2}$ & 0.0009 & 0.0033 & 0.0004 \\
\hline $\mathrm{SC}_{3,3}$ & 0.0006 & 0.0022 & 0.005 \\
\hline $\mathrm{SC}_{3,4}$ & 0.0025 & 0.0125 & 0.0125 \\
\hline $\mathrm{SC}_{3,5}$ & 0.0034 & 0.0034 & 0.0103 \\
\hline $\mathrm{SC}_{3,6}$ & 0.0049 & 0.0148 & 0.0148 \\
\hline $\mathrm{SC}_{4,1}$ & 0.0025 & 0.0069 & 0.0013 \\
\hline $\mathrm{SC}_{4,2}$ & 0.0024 & 0.0057 & 0.0015 \\
\hline $\mathrm{SC}_{4,3}$ & 0.0066 & 0.0076 & 0.0029 \\
\hline $\mathrm{SC}_{4,4}$ & 0.0077 & 0.024 & 0.0088 \\
\hline $\mathrm{SC}_{4,5}$ & 0.003 & 0.0124 & 0.0018 \\
\hline $\mathrm{SC}_{4,6}$ & 0.0095 & 0.0149 & 0.004 \\
\hline $\mathrm{SC}_{5,1}$ & 0.147 & 0.0368 & 0.147 \\
\hline $\mathrm{SC}_{5,2}$ & 0.0392 & 0.0098 & 0.0392 \\
\hline $\mathrm{SC}_{5,3}$ & 0.0122 & 0.0047 & 0.0212 \\
\hline $\mathrm{SC}_{6,1}$ & 0.0052 & 0.0143 & 0.0036 \\
\hline $\mathrm{SC}_{6,2}$ & 0.0116 & 0.032 & 0.0081 \\
\hline $\mathrm{SC}_{6,3}$ & 0.02 & 0.0927 & 0.0356 \\
\hline Final priority of alternatives & 0.3089 & 0.3375 & 0.3567 \\
\hline
\end{tabular}




\section{RESULTS AND DISCUSSION}

Based on the data from table- 1 and the criteria and subcriteria under consideration, pair wise comparison matrices have been developed for criteria verses criteria with respect to goal, sub-criteria verses sub-criteria with respect to the respective criterion. Outcome of all these pair wise comparison matrices is to obtain priority vector of the criteria with respect to goal and priority vectors of subcriteria with respect to the criterion. All those priorities have been presented in the tables 2 to 6 . Then chosen alternatives have been compared with each other in the light of two main criteria $\mathrm{C} 1$ and $\mathrm{C} 2$ and eighteen sub-criteria $\mathrm{SC} 3,1$ to $\mathrm{SC} 3,6$, $\mathrm{SC}_{4,1}$ to $\mathrm{SC}_{4,6}, \mathrm{SC}_{5,1}$ to $\mathrm{SC}_{5,3}$ and $\mathrm{SC}_{6,1}$ to $\mathrm{SC}_{6,3}$. Figure-2 demonstrates graphically, alternatives' priorities with respect to criteria $\mathrm{C} 1$ and $\mathrm{C} 2$ and also with respect to some of the sub-criteria. Nowglobal priority of an alternative with respect to a criterion is obtained by multiplying the priority of the alternative with respect to the chosen criterion and priority value of that criterion with respect to goal. For example, priority of the alternative $\mathrm{A}$ with respect to criterion $\mathrm{C} 1$ is 0.1062 . Priority value of the criterion $\mathrm{C} 1$ with respect to goal is 0.0415 . Then global priority of the alternative with respect to the criterion is product of 0.1062 and 0.0415 , ie 0.0044 . Similarly for the alternative B, priority value with respect to sub-criteria $\mathrm{SC}_{3,3}$ is 0.2828 . Priority value of $\mathrm{SC}_{3,3}$ with respect to the criterion $\mathrm{C} 3$ is 0.0759. And priority value of $\mathrm{C} 3$ with respect to goal is 0.1012 . Then global priority of the alternative $\mathrm{B}$ with respect to $\mathrm{SC}_{3,3}$ is product of priority values, $0.2828,0.0759$ and 0.1012 , ie 0.0022 . In a similar manner final priorities of alternatives with respect to criteria and sub-criteria have been obtained and presented in the table-7. When global priorities of an alternative are summed up, final priority of that alternative will be obtained. An alternative may dominate with respect to a particular criterion, as is evident from the figure-2, but it is the sum of the global priorities which will decide the ranking of an alternative. Table-7 also presents the synthesis of alternatives. From the table-7, it is clear that alternative $\mathrm{C}$ has highest priority value, and it is ranked number one, followed by $\mathrm{B}$ and finally $\mathrm{C}$.

\section{CONCLUSION}

Robotic spot welding is prevailing in automobile industries to manufacture the bodies made of sheet metal. Right choice of robot is utmost essential for quality spot welding. When number of alternative robots is available in the market, careful selection of one among them demands a systematic procedure. In the present work AHP has been implemented to evaluate the most appropriate robot to carry out the spot welding operation based on the technical factors.

\section{REFERENCES}

[1] CelikParkan, Ming-Lu Wu (1999) Decision-making and performance measurement models with applications to robot selection, $\mathbf{J}$ of Computers and Industrial Engineering, 363:503-523.

[2] FarzadTahriri et al (2008), AHP approach for supplier evaluation and selection in a steel manufacturing company, $\mathbf{J}$ of industrial engineering and management, 012: 54-76.

[3] Gin-Shuh Liang et al (1993)Fuzzy multi-criteria decision making approach for robot selection, $\mathbf{J}$ of Elsevier, Amsterdam, PAYS-BAS, 10:267-274.

[4] Groover MP (2003), Automation, Production System and CIM, Prentice Hall, India.

[5] M P Grover MP (2012), Industrial Robotics Technology, Programming and Applications, McGraw Hill, India.

[6] James Womack et al (2007) The Machine that changed the world, Simon \& Schuster, London.

[7] Mehmet CagatayBahadir, SuleItirSatoglu (2012), A Decision Support System for Robot Selection based on Axiomatic Principles, Proceedings of 2012 International Conference on Industrial Engineering and Operations Management, Isthambul, Turkey, July 3-6.

[8] Omkarprasad S. Vaidya, Sushil Kumar (2006), Analytic hierarchy process: An overview of applications, European $\mathrm{J}$ of Operational Research 169:1-29.

[9] Rishi kumar, R. K. Garg(2010), Optimal selection of robots by using distance based approach method, J of Robotics and Computer-Integrated Manufacturing 265:500-506.

[10] ŞenimÖzgürler et al (2011) Robot selection for a flexible manufacturing systemWith ahp and topsis methods, 15th International Research/Expert Conference"Trends in the Development of Machinery and Associated Technology"1 TMT 2011, Prague, Czech Republic, 12-18 September.

[11] Sharma M.J., Moon I., Bae H (2008) Analytic hierarchy process to assess and optimize distribution network, J of Applied Mathematics and Computation, 202: 256-265.

[12] Thomas L Saaty (1990), How to Make Decision: Analytic Hierarchy Process, European Journal of Operations Research 48:9-26.

[13] William Ho (2008), Integrated analytic hierarchy process and its applications - A literature review, European Journal of Operational Research 186: 211 228.

[14] http://www.qualitygurus.com/ accessed on 10-42016.

[15] www.robot.welding.com/ accessed on 7-4-16.

[16] https://robotics.kawasaki.com/ accessed on 7-4-16.

[17] www.Fanucrobotics.com accessed on 7-4-16

[18] www.motoman.com accessed on 7-4-16 